\title{
Influence of Alkalis on Natural Carbonation of Limestone Calcined Clay Cement Pastes
}

\author{
Ruoying Li and Hailong Ye* \\ Department of Civil Engineering, The University of Hong Kong, Pokfulam, Hong Kong, China; \\ liry@connect.hku.hk \\ * Correspondence: hlye@hky.hk; Tel.: +852-39178132
}

Citation: Li, R.; Ye, H. Influence of Alkalis on Natural Carbonation of Limestone Calcined Clay Cement Pastes. Sustainability 2021, 13, 12833. https://doi.org/10.3390/su132212833

Academic Editor: José

Ignacio Alvarez

Received: 27 October 2021

Accepted: 18 November 2021

Published: 19 November 2021

Publisher's Note: MDPI stays neutral with regard to jurisdictional claims in published maps and institutional affiliations.

Copyright: (c) 2021 by the authors. Licensee MDPI, Basel, Switzerland. This article is an open access article distributed under the terms and conditions of the Creative Commons Attribution (CC BY) license (https:// creativecommons.org/licenses/by/ $4.0 /)$.

\begin{abstract}
Vulnerability to atmospheric carbonation is one of the major durability concerns for limestone calcined clay cement $\left(\mathrm{LC}^{3}\right)$ concrete due to its relatively low overall alkalinity. In this study, the natural carbonation behaviors of ternary ordinary Portland cement-metakaolin-limestone (OPC-MK-LS) blends containing various sulfate salts (i.e., anhydrous $\mathrm{CaSO}_{4}, \mathrm{Na}_{2} \mathrm{SO}_{4}$, and $\mathrm{K}_{2} \mathrm{SO}_{4}$ ) are studied, with the aim of revealing the influence of alkali cations $\left(\mathrm{Na}^{+}, \mathrm{K}^{+}\right)$. Detailed analyses on the hydrated phase assemblage, composition, microstructure, and pore structure of $\mathrm{LC}^{3}$ pastes prior to and post indoor carbonation are conducted. The results show that the incorporation of sulfate salts accelerates the setting and strength gain of $\mathrm{LC}^{3}$ pastes, likely through enhancement of ettringite formation, but undermines its later age strength achievement due to the deleterious effect of alkali cations $\left(\mathrm{Na}^{+}, \mathrm{K}^{+}\right)$on late age OPC hydration. The carbonation resistance of $\mathrm{LC}^{3}$ systems is considerably undermined, particularly with the incorporation of $\mathrm{Na}_{2} \mathrm{SO}_{4}$ or $\mathrm{K}_{2} \mathrm{SO}_{4}$ salts, due to the simultaneous pore coarsening effect and reduced $\mathrm{CO}_{2}$-binding capacity. The carbonation-induced phase and microstructural alterations of $\mathrm{LC}^{3}$ pastes are discussed and compared with those of reference OPC pastes.
\end{abstract}

Keywords: limestone calcined clay cement; low-carbon binder; natural carbonation; durability of concrete

\section{Introduction}

Limestone calcined clay cement $\left(\mathrm{LC}^{3}\right)$, manufactured by blending limestone, calcined clay, and Portland cement (including gypsum) in an approximate 1:2:3 mass ratio, is a promising low-carbon binder. As the production of calcined clay and limestone powders requires much less energy and emits less carbon dioxide than that of ordinary Portland cement (OPC), the use of $\mathrm{LC}^{3}$ can enhance the eco-efficiency of concrete construction $[1,2]$. Moreover, existing studies have shown that $\mathrm{LC}^{3}$ concrete has comparable mechanical performance as OPC counterparts, as well as higher resistance to chloride and sulfate attack and alkali-silica reaction [3-6]. However, $\mathrm{LC}^{3}$ concrete tends to have relatively poor carbonation resistance due to its lower overall calcium content $[4,7,8]$, thus increasing the corrosion risk of steel reinforcement embedded in concrete [9-11]. There is hence a need to understand the factors influencing the carbonation behaviors of $\mathrm{LC}^{3}$ concrete, and to design new formulations with enhanced carbonation resistance.

Many previous studies have documented that alkalis have dramatic effects on the hydration kinetics and microstructural development, as well as mechanical and durability performance of hardened OPC materials [12,13]. For instance, it was reported that the alkali salt contamination in OPC accelerates carbonation, deepening the carbonation depth, and shortening the initiation time of carbonation-induced steel corrosion [14]. Moreover, alkali increases the alkalinity level of pore solution, and influences the precipitation rate of calcium carbonate [15], thus increasing the carbonation rate of concrete. However, few studies are available in the literature regarding the influence of alkali on the properties of $\mathrm{LC}^{3}$ systems [16], particularly concerning its carbonation resistance. Given the high 
intrinsic vulnerability of $\mathrm{LC}^{3}$ binders to carbonation, the role of alkalis on its atmospheric carbonation behaviors needs further investigation.

In $\mathrm{LC}^{3}$ concrete, the alkali cations $\left(\mathrm{Na}^{+}\right.$and $\mathrm{K}^{+}$) come from either the composition of clinker (e.g., thenardite, arcanite), clay minerals (e.g., up to $4 \%$ equivalent $\mathrm{Na}_{2} \mathrm{O}$ in some natural clays [17]), limestone, aggregate, or from the exposed alkali-bearing environments (e.g., seawater, deicer). The total reactive alkali content in $\mathrm{LC}^{3}$ systems varies depending on the chemistry of raw materials and the reactivity and alkali-releasing rates of alkalibearing constituents. Although it may be impractical to incorporate extra alkali into LC $^{3}$ to potentially enhance the dissolution and reaction of calcined clays and limestone (due to, e.g., alkali-silica reaction risk [18]), investigating the influence of alkali on properties of $\mathrm{LC}^{3}$ could advance our understanding of its reaction mechanisms. Moreover, the increased level of alkali may lift the $\mathrm{pH}$ of pore solution in $\mathrm{LC}^{3}$ systems and thus boost its $\mathrm{CO}_{2}$ binding capacity. Nevertheless, how the supplemented alkalis could affect the carbonation resistance of $\mathrm{LC}^{3}$ cementitious systems remains largely unknown and unexplored.

The main objective of this study is to investigate the influence of three sulfate salts (i.e., anhydrous $\mathrm{CaSO}_{4}, \mathrm{Na}_{2} \mathrm{SO}_{4}$, and $\mathrm{K}_{2} \mathrm{SO}_{4}$ ) on the setting and hardening, strength development, hydrated phase assemblage, composition, microstructure, and carbonation resistance of $\mathrm{LC}^{3}$ pastes, towards uncovering the mechanisms by which alkali cation $\left(\mathrm{Na}^{+}\right.$ and $\mathrm{K}^{+}$) affects its carbonation behaviors. The consideration of using sulfate-bearing salts in this study, rather than other types of salts (e.g., $\mathrm{NaOH}, \mathrm{KOH}$ ), is because additional sulfate (typically from gypsum) is usually needed in Portland cement-metakaolin-limestone blends to prevent undersulfation [3]. In addition, the natural carbonation behaviors of LC $^{3}$ pastes are analyzed and compared with those of reference OPC paste. This work contributes to the mixture design of low-carbon binders for reinforced concrete applications.

\section{Materials and Methods}

\subsection{Materials and Mixture}

The $\mathrm{LC}^{3}$ is formulated by blending OPC, calcined high-grade kaolinite (metakaolin, $\mathrm{MK}$ ), and limestone (LS) powders. The oxide composition and granulometric distributions of the raw powders determined by X-ray fluorescence and X-ray laser diffraction are shown in Table 1 and Figure 1, respectively. It should be noted that the MK and LS powders are substantially finer than the OPC, which could alter its hydration kinetics via filler effects.

Table 1. Oxide composition of raw powders.

\begin{tabular}{cccc}
\hline Oxide Composition (wt.\%) & OPC & Metakaolin & Limestone \\
\hline $\mathrm{CaO}$ & 66.48 & - & 54.57 \\
$\mathrm{SiO}_{2}$ & 20.17 & 55.31 & - \\
$\mathrm{Al}_{2} \mathrm{O}_{3}$ & 4.01 & 43.55 & 0.08 \\
$\mathrm{MgO}_{\mathrm{SO}}$ & 0.85 & - & 0.95 \\
$\mathrm{Fe}_{2} \mathrm{O}_{3}$ & 5.13 & - & 0.07 \\
$\mathrm{Na}_{2} \mathrm{O}$ & 2.77 & 0.44 & 0.03 \\
$\mathrm{~K}_{2} \mathrm{O}$ & - & - & - \\
$\mathrm{MnO}$ & 0.58 & - & - \\
$\mathrm{TiO}_{2}$ & - & - & - \\
$\mathrm{LOI}$ at $900{ }^{\circ} \mathrm{C}$ & - & 0.7 & - \\
\hline
\end{tabular}

Note: The oxide composition was determined by X-ray fluorescence, and the LOI was determined by thermogravimetric analysis. '-' means trace amount.

The mixture proportion of designed $\mathrm{LC}^{3}$ pastes is detailed in Table 2. The $\mathrm{LC}^{3}$ pastes with a constant $45 \%$ OPC substitution level by a combined MK and LS at a constant mass ratio of 2:1, and with a constant water-to-powder $(\mathrm{w} / \mathrm{p})$ ratio of 0.4 , are prepared. In addition to the pure OPC paste, a control mixture with $45 \%$ quartz powder replacement (denoted as OPC_45Q) is considered, to distinguish the potential filler effects from the chemical effects of $\mathrm{MK}$ and LS reaction in $\mathrm{LC}^{3}$ systems. To investigate the effects of alkali incorporation on the hydration and carbonation behaviors of $\mathrm{LC}^{3}$ pastes, $2.5 \%$ 
OPC is replaced by anhydrous calcium sulfate $\left(\mathrm{CaSO}_{4}, \mathrm{Cs}\right)$, sodium sulfate $\left(\mathrm{Na}_{2} \mathrm{SO}_{4}, \mathrm{Ns}\right)$, or potassium sulfate $\left(\mathrm{K}_{2} \mathrm{SO}_{4}, \mathrm{Ks}\right)$ salts. The replacement level of OPC by sulfate salts were determined based on preliminary trials considering the strength development and fresh properties. It should be noted that, typically, additional sulfates are required to be supplemented to $\mathrm{LC}^{3}$ systems in order to achieve proper sulfate balance by compensating the acceleration of aluminate peak in the isothermal calorimetry tests, due to the filler effect of MK and LS [19]. All the dry solid powders including OPC, MK, LS, and sulfate salts were blended for at least $5 \mathrm{~min}$ in a Hobart mixer before adding mixing water. A commercial polycarboxylate-based superplasticizer was added to ensure uniformity and homogeneity of the formed paste samples. The casted samples were vibrated on a shaking table for approximately $30 \mathrm{~s}$ to dissipate trapped air and ensure compactness.

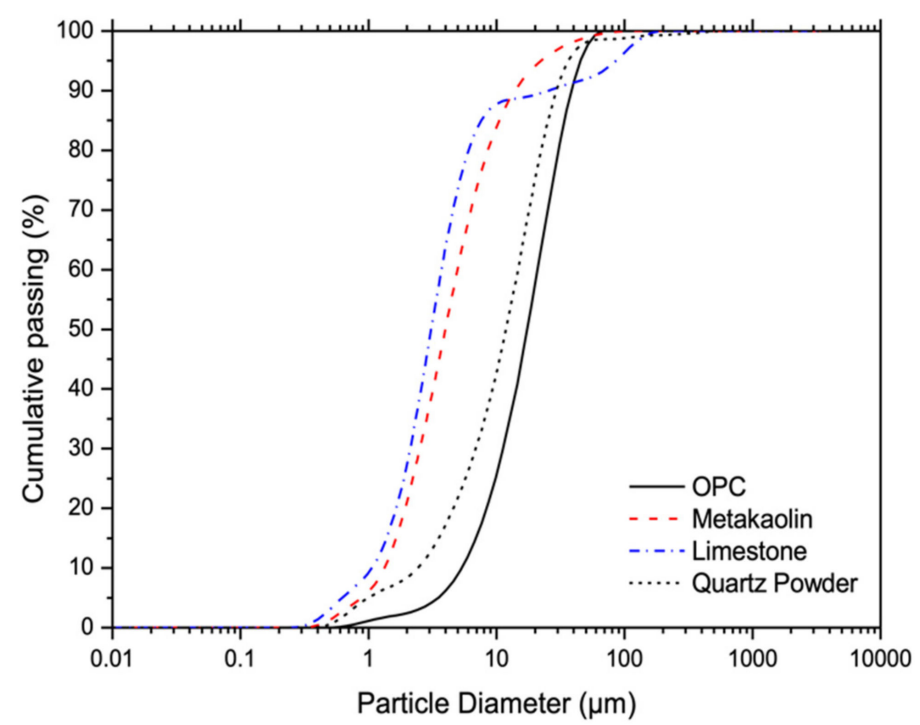

Figure 1. Particle size distributions of raw solid powders including OPC, metakaolin, limestone, and quartz powder.

Table 2. Mixture parameters of reference $\mathrm{OPC}$ and $\mathrm{LC}^{3}$ pastes containing various sulfate salts.

\begin{tabular}{ccccccccc}
\hline Mixture ID & OPC (\%) & MK (\%) & LS (\%) & QP (\%) & $\begin{array}{c}\mathrm{CaSO}_{4} \\
\mathbf{( \% )}\end{array}$ & $\begin{array}{c}\mathbf{N a}_{2} \mathbf{S O}_{4} \\
\mathbf{( \% )}\end{array}$ & $\begin{array}{c}\mathbf{K}_{2} \mathbf{S O}_{4} \\
(\mathbf{\%})\end{array}$ & w/p ${ }^{\text {a }}$ \\
\hline OPC & 100.0 & - & - & - & - & - & - & \\
OPC_45Q & 55.0 & - & - & 45.0 & - & - & - & \\
LC & 55.0 & 30.0 & 15.0 & - & - & - & - & 0.4 \\
LC $^{3}$ _Cs & 52.5 & 30.0 & 15.0 & - & 2.5 & - & - & \\
LC $^{3}$ _Ns & 52.5 & 30.0 & 15.0 & - & - & 2.5 & - & \\
LC $^{3} \_$Ks & 52.5 & 30.0 & 15.0 & - & - & - & 2.5 &
\end{tabular}

All percentages are mass-based. ${ }^{\mathrm{a}}: \mathrm{w} / \mathrm{p}$ represents water-to-powder ratio, in which powder includes OPC, MK (metakaolin), LS (limestone), QP (quartz powder), and sulfate salts.

\subsection{Vicat Setting Test}

Needle penetration tests using an automatic Vicat apparatus (ELE International) were conducted following ASTM C 191 [20] to investigate the setting behaviors of paste samples. It should be noted that the pastes were prepared according to the mixture parameters in Table 2, without adjustment to the normal consistency. Fresh pastes were poured into a conical mold with a $40 \mathrm{~mm}$ height, $90 \mathrm{~mm}$ inner bottom diameter, and $80 \mathrm{~mm}$ inner top diameter. The penetration depth of a 1-mm Vicat needle settled into the paste samples was recorded as a function of hydration time.

\subsection{Compressive Strength}

The pastes were cast in $40 \mathrm{~mm}$ cubic molds and demolded after $23 \pm 1 \mathrm{~h}$, followed by curing in sealed bags stored in a closed moist cabinet until reaching designated ages 
for further tests. The compressive strength of hardened specimens was measured at 1, 7, and 28 days of hydration age with three replicates, using a compression machine (ELE International) at a loading speed of $3 \mathrm{kN} / \mathrm{s}$.

\subsection{Phase Analysis Prior to Carbonation}

To investigate the effects of alkali incorporation on the phase assemblage and microstructure of $\mathrm{LC}^{3}$ pastes, detailed characterization on hardened paste samples at ages of 1 and 28 days was conducted using X-ray diffraction (XRD), thermogravimetric analysis (TGA), and Fourier transform infrared spectroscopy (FTIR). The pastes samples were cast and cured in sealed polypropylene vials at room temperature after mixing, to minimize any potential carbonation during curing periods. After reaching the designated ages, the samples were sliced into discs of $\sim 2 \mathrm{~mm}$ in thickness using a low-speed diamond saw, and then immersed in excessive isopropyl alcohol for immediate hydration arrestment. Afterwards, the samples were vacuum dried at $40^{\circ} \mathrm{C}$ for at least $72 \mathrm{~h}$. The dried samples were pulverized into powders passing through a $150 \mu \mathrm{m}$ sieve. The same powder samples were analyzed by different characterization techniques, as will be described later.

The XRD was used to investigate the crystalline phase evolution of $\mathrm{LC}^{3}$ pastes, particularly concerning the formation of AFt and AFm phases (i.e., calcium aluminate phases). The PANalytical X'Pert PRO X-ray diffractometer in a Bragg-Brentano $\theta-2 \theta$ configuration with $\mathrm{Cu} \mathrm{K} \alpha$ X-ray $(\lambda=0.1541 \mathrm{~nm})$, under a working voltage of $40 \mathrm{kV}$ and beam current of $40 \mathrm{~mA}$, was used. The XRD patterns were collected across a $2 \theta$ range from 5 to $40^{\circ}$ at a step of $0.03342^{\circ}$. The TGA enabled the identification of amorphous and crystalline phases, complementing XRD, as well as allowed for straightforward quantifications of mass percentages of portlandite $(\mathrm{CH})$ and calcium carbonates $(\mathrm{Cc})$ in samples. In this work, the decomposition temperature ranges of $\mathrm{CH}$ and $\mathrm{Cc}$ were set at $420-520{ }^{\circ} \mathrm{C}$ and 520 to $900{ }^{\circ} \mathrm{C}$, respectively. Moreover, as bimodal peaks related to the decomposition of $\mathrm{Cc}$ were observed (due to varying levels of crystallization [21]) in samples, the temperature ranges at $520-720{ }^{\circ} \mathrm{C}$ and $720-900{ }^{\circ} \mathrm{C}$ were assigned to the less-crystalline $\mathrm{Cc}$ and morecrystalline $\mathrm{Cc}$, respectively. Approximately $50 \mathrm{mg}$ dry powders were loaded in the ceramic crucibles of PerkinElmer TGA 4000, and then heated from 30 to $900{ }^{\circ} \mathrm{C}$ with a heating rate of $20^{\circ} \mathrm{C} / \mathrm{min}$ and nitrogen purged at $20 \mathrm{~mL} / \mathrm{min}$. The FTIR equipped with attenuated total reflection was adopted to acquire the infrared spectra of samples from 4000 to $600 \mathrm{~cm}^{-1}$ using PerkinElmer FTIR Frontier.

\subsection{Natural Carbonation}

Carbonation of cementitious matrices is a reactive-transport process, involving the transport of gaseous $\mathrm{CO}_{2}$ in pore networks and its reaction with hydrated phases. To distinguish the $\mathrm{CO}_{2}$ transport effects from the chemical effects (i.e., the $\mathrm{CO}_{2}$ binding) on the overall carbonation resistance of cementitious matrices, both bulk and powder samples were prepared [22].

Powder samples: The purpose of using powder samples is to eliminate the potential differences in mass transport properties among different mixtures, hence allowing for specific investigation of carbonation-induced phase and molecular alterations. After 28 days of sealed curing at room temperature, the matured samples were pulverized, passing through a $150 \mu \mathrm{m}$ sieve, and subsequently exposed to an indoor environment (approximately 60\% relative humidity and $20^{\circ} \mathrm{C}$ on average) for natural carbonation. The powder samples were periodically stirred to facilitate uniform carbonation. The phase assemblage of carbonated samples at various time intervals up to 90 days was studied by XRD, TGA, and FTIR, using the same sample preparation procedures and instrumental parameters described before.

Bulk samples: After 28 days of sealed curing at room temperature, $40 \mathrm{~mm}$ cubic specimens were exposed to the same indoor carbonation environment as the powder samples. After being carbonated for 23 weeks, the specimens were split and sprayed with phenolphthalein solution for carbonation depth determination. Given that the carbonated zone was uncolored, whilst the non-carbonated core was purple-colored, the 
average carbonation depth was estimated via image processing (Image ${ }^{\circledR}$ ) of the photos of colored specimens [23]. Meanwhile, scanning electron microscopy equipped with energydispersive X-ray spectroscopy (SEM-EDS) was used to investigate the microstructural and compositional alterations at the skin layers of the carbonated bulk specimens using the Hitachi S3400 SEM. After being carbonated for 23 weeks, the slices covering the carbonated zone (uncolored proportion) were segmented and then vacuum-dried after being solventexchanged to minimize disruptions on the microstructure of samples. The samples were impregnated with epoxy resin, and polished down to $1 \mu \mathrm{m}$. Carbon coating and conductive silver adhesives were applied to avoid sample charging during SEM-EDS data acquisition. To accommodate for the compositional heterogeneity in the cementitious microstructure, 20-50 microanalysis points were randomly selected on the hydrated products (avoiding unreacted particles) in each sample [24].

\subsection{Pore Size Distribution Analysis}

The mercury intrusion porosimetry (MIP) was capable of measuring the pore size distribution of hardened pastes down to approximately $3 \mathrm{~nm}$ [25]. To investigate the effects of carbonation on pore structure alterations of pastes, MIP was conducted on samples without and with carbonation using the Micromeritics AutoPore IV 9500. In particular, the cubes after 23 weeks of natural carbonation after 28 days of sealed curing, as well as the uncarbonated (sealed) samples of the same ages (i.e., 27 weeks), were analyzed. Since the degree of carbonation was depth-dependent in the carbonated specimens, the skin layer uncolored by phenolphthalein solution in the $\mathrm{LC}^{3}$ pastes was sampled for MIP tests, while for the reference OPC paste, the outermost $\sim 2 \mathrm{~mm}$ layer was sampled. It should be noted that due to the differences in carbonation resistance (carbonation depth) among various mixtures, the level of carbonation in the sampled layers may not be consistent. The samples were soaked in isopropyl alcohol and dried under vacuum pumping at $40{ }^{\circ} \mathrm{C}[25,26]$. A contact angle of $130^{\circ}$ and the maximum pressure of $414 \mathrm{MPa}$ under continuous mode was employed.

\section{Results and Discussion}

\subsection{Setting Times}

The time-dependent Vicat penetration depths of reference OPC and $\mathrm{LC}^{3}$ pastes are plotted in Figure 2. It can be seen that the $\mathrm{LC}^{3}$ pastes show faster setting behaviors over the OPC counterpart, likely attributed to the dominant filler effects of MK and LS powders. Similar observations were reported in the previous $\mathrm{LC}^{3}$ studies [4,27-30]. Alternatively, the high water demand of MK may reduce the amount of water available for OPC hydration, thus shortening the time to reach supersaturation with respect to the hydrated phases [28]. Moreover, the incorporation of sulfate salts, regardless of the conjugated cation type, noticeably shortens the setting time of $\mathrm{LC}^{3}$ pastes. The acceleration role of alkalis on earlyage hydration of cementitious systems is also reported in pure OPC systems [12,31,32].

\subsection{Strength Development}

The compressive strength development of reference OPC and $\mathrm{LC}^{3}$ pastes as a function of age is shown in Figure 3. Consistent with the trends reported in the literature [3,33], $\mathrm{LC}^{3}$ systems show relatively low strength achievement at early ages, but then surpass that of reference OPC with the same $\mathrm{w} / \mathrm{p}$ ratio at later stages, owing to continued pozzolanic reaction of MK. Moreover, consistent with the observation in the pure OPC system [31,34], the incorporation of alkali ( $\mathrm{Na}$ or $\mathrm{K}$ ) in $\mathrm{LC}^{3}$ systems accelerates its early-age strength gain, but shows a detrimental effect at later ages. The acceleration effect of sulfates on setting and strength achievement of $\mathrm{LC}^{3}$ systems could be related to the enhanced formation of ettringite (which will be elaborated upon later); however, the reduction in later-age strength is likely attributed to the increased porosity in cementitious matrices (which will be elaborated upon later) due to a reduced degree of hydration. In addition, in comparison to the $\mathrm{LC}^{3}$ containing $\mathrm{CaSO}_{4}$ salt, the reduction in later-age strength is more significant in 
the $\mathrm{Na}_{2} \mathrm{SO}_{4}$ - or $\mathrm{K}_{2} \mathrm{SO}_{4}$-admixed counterparts, suggesting the potential deleterious role of alkali cation (i.e., $\mathrm{Na}^{+}$and $\mathrm{K}^{+}$) on the diffusion-controlled hydration process. One potential reason is that the incorporation of $\mathrm{Na}^{+}$and $\mathrm{K}^{+}$modifies the atomic structure and density of calcium-silicate-hydrate (C-S-H) [31], and then slows down late hydration kinetics by delaying the transport of dissolved elements from the reactive OPC grains [35].

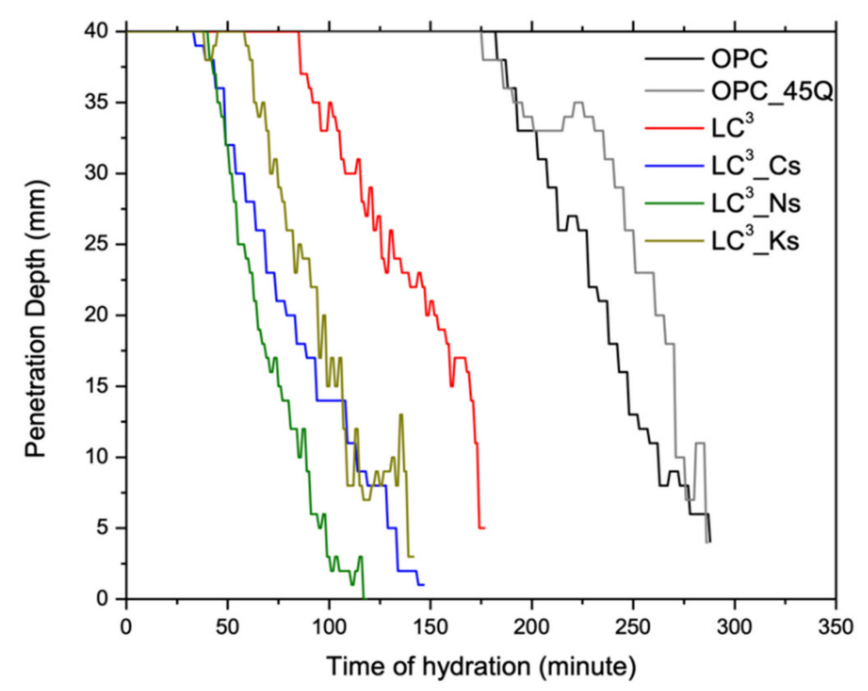

Figure 2. Time-dependent Vicat penetration depths for reference OPC and $\mathrm{LC}^{3}$ pastes.

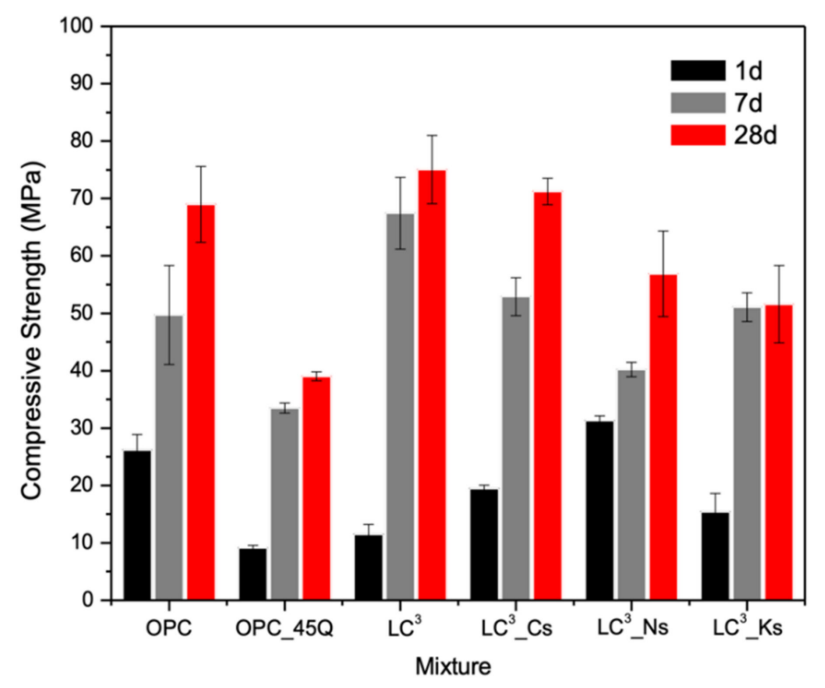

Figure 3. Compressive strengths of seal-cured OPC and $\mathrm{LC}^{3}$ paste specimens at 1,7 , and 28 days. The error bar represents the standard deviation of three measurements.

\subsection{Phase Assemblage Prior to Carbonation}

The XRD patterns, thermogravimetric and derivative thermogravimetric (TG-DTG) diagrams, and FTIR spectra of reference OPC and $\mathrm{LC}^{3}$ pastes at ages of 1 and 28 days are shown in Figures 4-6. In comparison to the OPC paste, the $\mathrm{LC}^{3}$ pastes, regardless of the type of sulfate salts incorporated, have substantially lower amounts of portlandite $(\mathrm{CH})$, but higher amounts of AFm phases, owing to the following reactions [36]:

$$
\begin{gathered}
3 \mathrm{CH}+\mathrm{AS}_{2}(\text { Metakaolin })+6 \mathrm{H} \rightarrow \mathrm{C}-\mathrm{A}-\mathrm{S}-\mathrm{H}+\mathrm{C}_{2} \mathrm{ASH}_{8} \\
\mathrm{C}_{3} \mathrm{~A}+0.5 \mathrm{Cc}+0.5 \mathrm{CH}+11.5 \mathrm{H} \rightarrow \mathrm{C}_{4} \mathrm{~A}_{\mathrm{C} 0.5} \mathrm{H}_{12}(\text { Hemicarbonate }) \\
\mathrm{AS}_{2}+0.5 \mathrm{Cc}+3.5 \mathrm{CH}+8.5 \mathrm{H} \rightarrow \mathrm{C}_{4} \mathrm{~A}_{\mathrm{C} 0.5} \mathrm{H}_{12}
\end{gathered}
$$



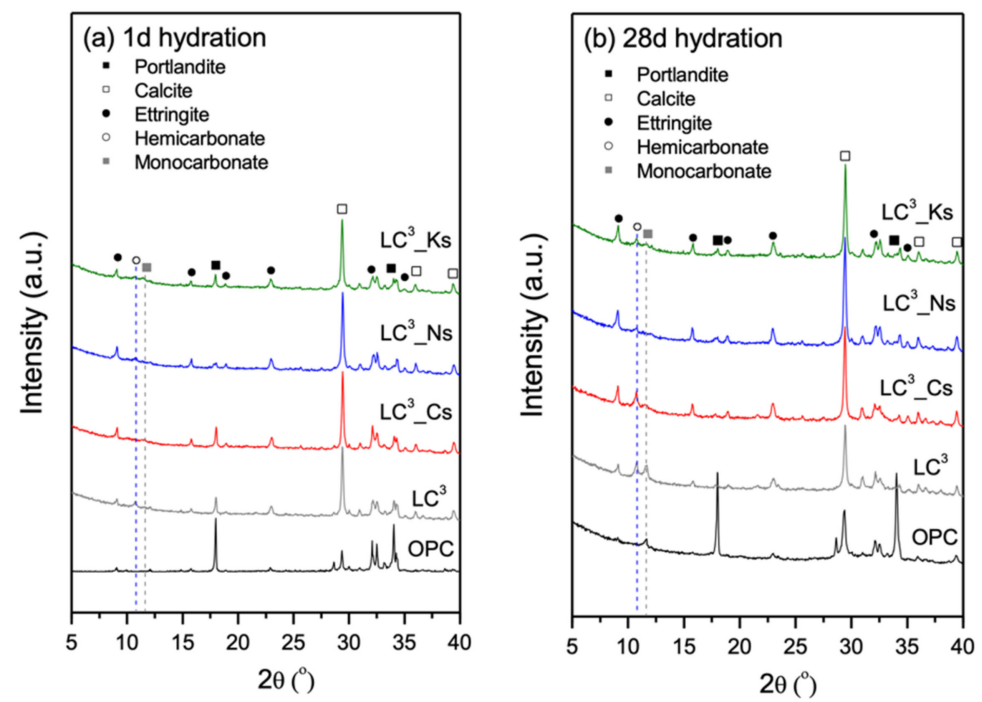

Figure 4. XRD patterns of reference OPC and $\mathrm{LC}^{3}$ pastes prior to carbonation at ages of (a) 1 day; (b) 28 days.
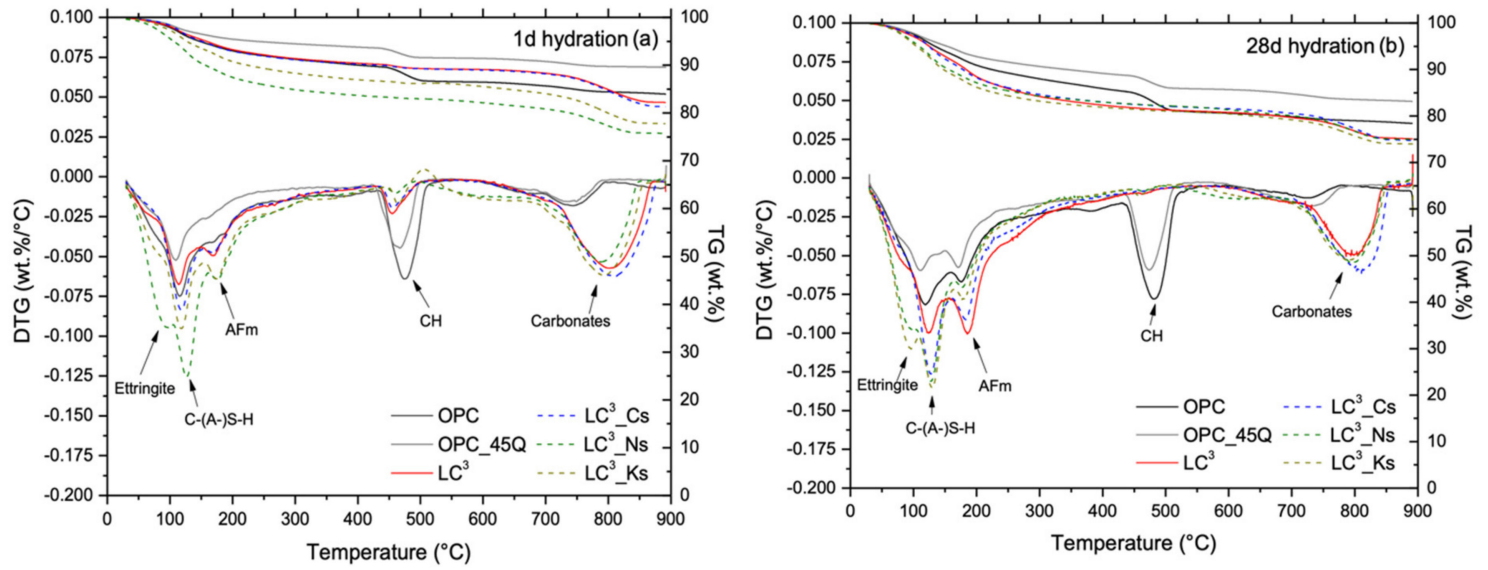

Figure 5. TG-DTG diagrams of reference OPC and $\mathrm{LC}^{3}$ pastes prior to carbonation at ages of (a) 1 day; (b) 28 days.
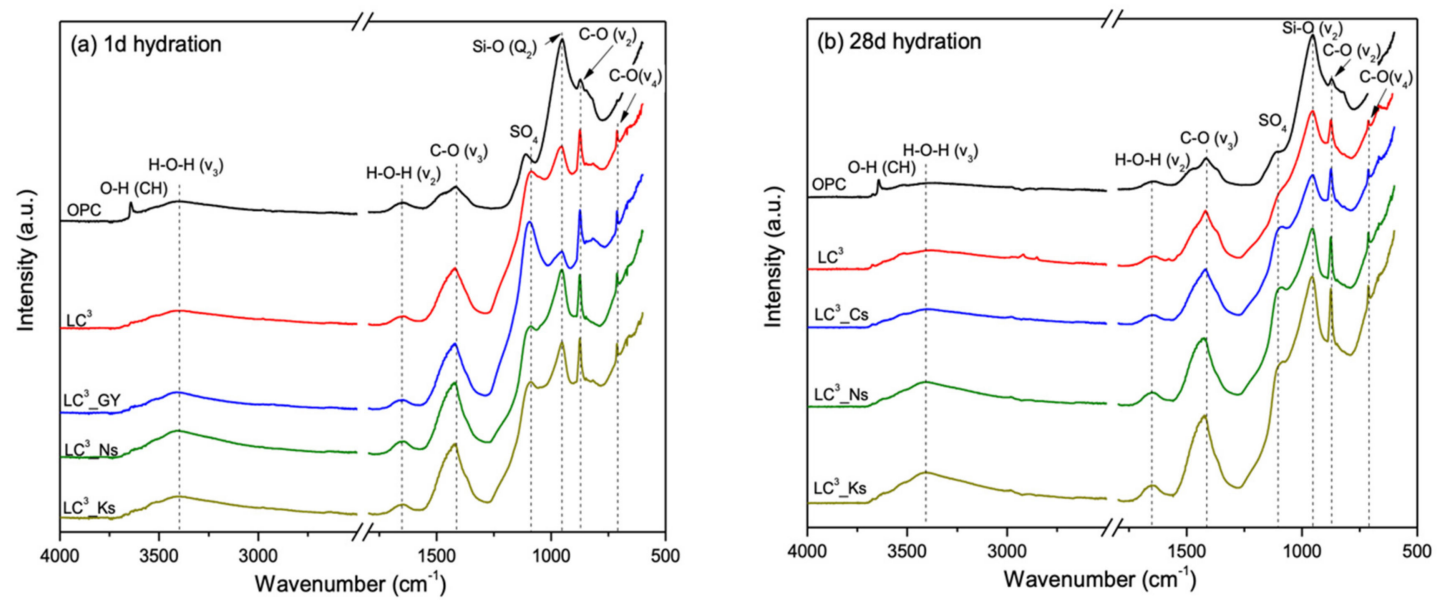

Figure 6. FTIR spectra of reference OPC and LC ${ }^{3}$ pastes prior to carbonation at ages of (a) 1 day; (b) 28 days.

At the age of 28 days, only a trace amount of $\mathrm{CH}$ is observed in $\mathrm{LC}^{3}$ systems, due to the high reactivity of $\mathrm{MK}$ adopted in this study. As evidenced in the XRD patterns, the AFm phases in plain $\mathrm{LC}^{3}$ systems are hemicarbonate $\left(\mathrm{C}_{4} \mathrm{Ac}_{0} \cdot{ }_{5} \mathrm{H}_{12}\right)$ and monocarbonate 
$\left(\mathrm{C}_{4} \mathrm{AcH}_{12}\right)$, in comparison to the reference OPC paste, in which only monocarbonate is observed at 28 days. However, the XRD peak intensity of AFm phases formed in $\mathrm{LC}^{3}$ containing sulfate salts seems to be lower than that of plain $\mathrm{LC}^{3}$ particularly at 28 days, likely due to the preferable AFt phases (ettringite) formation. It is not surprising, as the relative proportion of AFm and AFt phases in a cementitious system is highly influenced by the ratio of reactive sulfate and aluminate [37]. With the incorporation of sulfate salts, the formation of ettringite is noticeably enhanced, as evidenced in high-intensity XRD diffraction peaks, a distinctive mass loss hump at $\sim 70{ }^{\circ} \mathrm{C}$ in the TG-DTG diagrams, and an obvious hump assigned to S-O bands in the FTIR spectra. Meanwhile, the $\mathrm{CH}$ content in $\mathrm{LC}^{3}$ is reduced with the incorporation of sulfate salts, suggesting that the supplemented sulfate ions boost the ettringite precipitation in $\mathrm{LC}^{3}$ pastes via a potential reaction with $\mathrm{CH}$ and reactive alumina (from MK or $\mathrm{C}_{3} \mathrm{~A}$ ). On the other hand, the mass loss hump at around 100-150 ${ }^{\circ} \mathrm{C}$ assigned to aluminum-modified C-S-H (i.e., C-A-S-H) in $\mathrm{LC}^{3}$ systems shows larger intensity in those containing $\mathrm{Na}_{2} \mathrm{SO}_{4}$ or $\mathrm{K}_{2} \mathrm{SO}_{4}$ salts, indicating a modification of water-binding behavior of C-A-S-H with alkali $(\mathrm{Na}, \mathrm{K})$ incorporation.

The FTIR spectra of $\mathrm{LC}^{3}$ pastes at 1 day of hydration support the findings that the incorporation of sulfate salts accelerates the early-age hydration, as evidenced by a higher intensity of Si-O $\left(\mathrm{Q}_{2}\right)$ band at around $970 \mathrm{~cm}^{-1}$ assigned to the in-plane stretching vibration of the $\mathrm{Q}_{2}$ tetrahedra in C-A-S-H products [38,39]. Moreover, it is observed that the band at $1100 \sim 1200 \mathrm{~cm}^{-1}$, as assigned to the stretching vibration of $\mathrm{SO}_{4}{ }^{2-}[40,41]$ in the ettringite phase, is the most significant at 1 day, but then overwhelmed by the Si-O $\left(\mathrm{Q}_{2}\right)$ band hump at 28 days. In addition, the bands located are around $1417 \mathrm{~cm}^{-1}$ and $875 \sim 878 \mathrm{~cm}^{-1}$ are related to the vibration of C-O bonds [39], all of which are more significant for the $\mathrm{LC}^{3}$ system due to the presence of LS.

\subsection{Carbonation Resistance}

Figure 7 shows the photos of the sliced specimens sprayed with phenolphthalein solution and its corresponding average carbonation depths. It can be seen that $\mathrm{LC}^{3}$ pastes show considerably lower carbonation resistance than the reference OPC paste. Even under natural carbonation conditions, the average carbonation depth of $\mathrm{LC}^{3}$ pastes could reach approximately 2.4 to $4.5 \mathrm{~mm}$ in 23 weeks, depending on the type of conjugated cation. Moreover, it can be seen that that $\mathrm{Na}_{2} \mathrm{SO}_{4}$ and $\mathrm{K}_{2} \mathrm{SO}_{4}$ salts noticeably deepen the carbonation depth of $\mathrm{LC}^{3}$ pastes. The lowered carbonation resistance in $\mathrm{LC}^{3}$ with the incorporation of $\mathrm{Na}_{2} \mathrm{SO}_{4}$ or $\mathrm{K}_{2} \mathrm{SO}_{4}$ salts can be attributed to a reduced $\mathrm{CO}_{2}$ binding capacity and a coarsened pore structure, as will be discussed later.
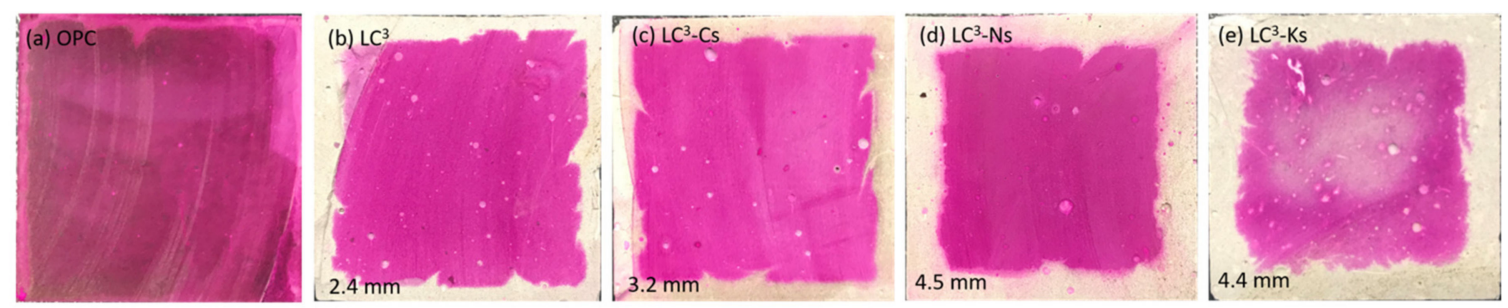

Figure 7. Photos of the sliced specimens sprayed with phenolphthalein after natural carbonation for 23 weeks after 28 days of sealed curing. (a) OPC; (b) $\mathrm{LC}^{3}$; (c) LC ${ }^{3} \_\mathrm{Cs}$; (d) $\mathrm{LC}^{3} \_\mathrm{Ns}$; (e) $\mathrm{LC}^{3}{ }_{-} \mathrm{Ks}$.

\subsection{Phase Alternations Post-Carbonation}

The XRD patterns, TG-DTG diagrams, and FTIR spectra of reference OPC and LC 3 pastes after natural indoor carbonation are shown in Figures 8-10. In the reference OPC paste, natural carbonation leads to a gradual consumption of $\mathrm{CH}$ and $\mathrm{AFm}$ phases, as accompanied by the precipitation of Cc (calcite and aragonite) [42,43]. Even after 90 days of carbonation, $\mathrm{CH}$ still exists while the peaks related to C-S-H gradually diminish, implying simultaneous carbonation of C-S-H and CH in OPC systems [44], while in $\mathrm{LC}^{3}$ systems, 
which contain little $\mathrm{CH}$ prior to carbonation, the peaks related to AFm and C-A-S-H are progressively reduced as carbonation advances. Moreover, two major humps associated with the carbonate pastes can be identified in the TG-DTG diagrams. As mentioned before, this is due to varying levels of crystallization of $\mathrm{Cc}_{\mathrm{C}}$ in samples [21]. Figure 11a shows the time-dependent evolution of mass percentages of $\mathrm{CH}$, less-crystalline $\mathrm{Cc}$, more-crystalline $\mathrm{Cc}$, and total $\mathrm{Cc}$ in the reference OPC and $\mathrm{LC}^{3}$ pastes. The carbonation of OPC leads to simultaneous growth of both less- and more-crystalline $\mathrm{Cc}$, while carbonation of $\mathrm{LC}^{3}$ leads to more significant growth of less-crystalline Cc. Although further verification is needed, the more-crystalline $\mathrm{Cc}$ may originate from the $\mathrm{CH}$ carbonation, while that of less-crystalline Cc may be related to the conversion of C-S-H, C-A-S-H, and AFm phases.
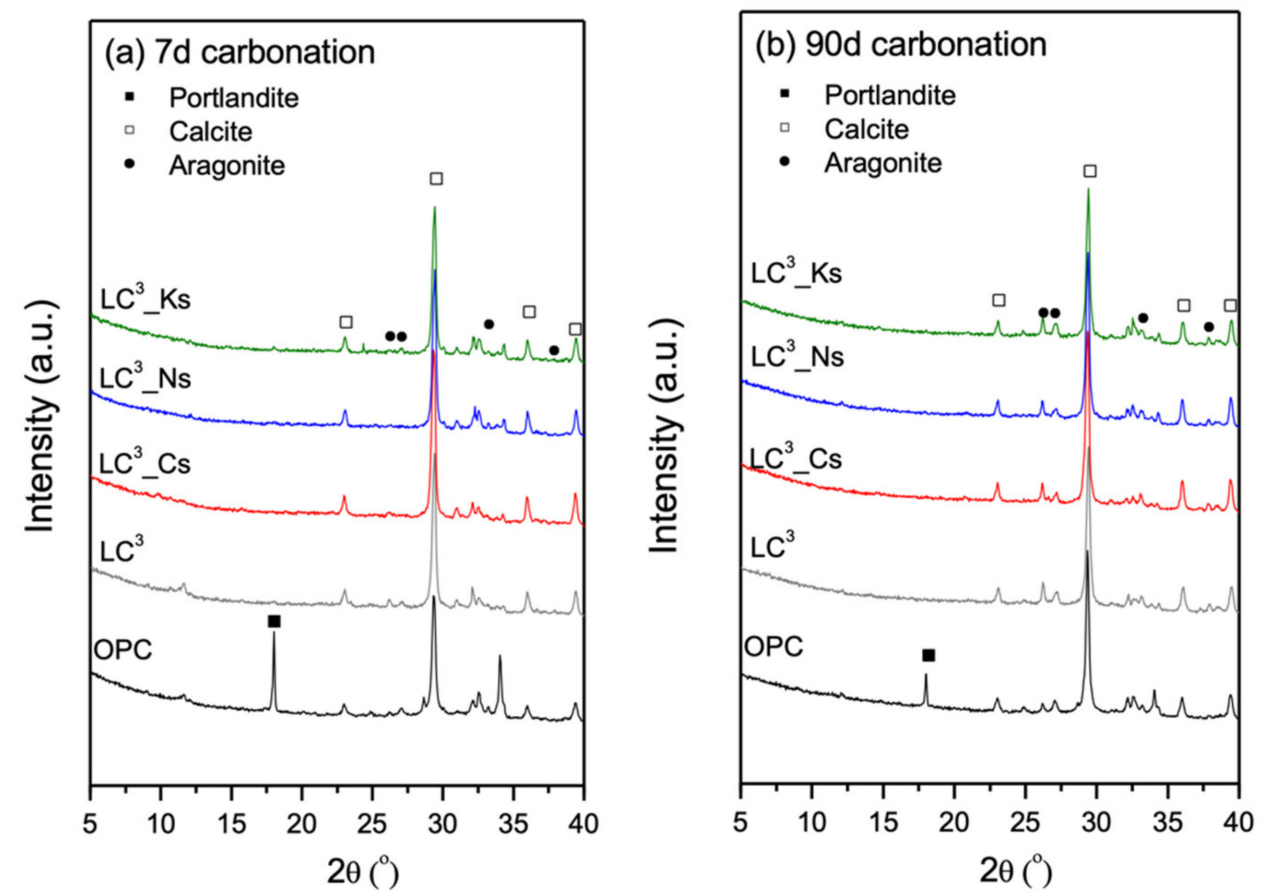

Figure 8. XRD patterns of reference OPC and $\mathrm{LC}^{3}$ pastes after natural carbonation for (a) 7 days; (b) 90 days.

To illustrate the $\mathrm{CO}_{2}$ binding capacity of $\mathrm{LC}^{3}$ pastes, the amount of $\mathrm{CO}_{2}$ uptake could be approximately estimated as:

$$
\mathrm{CO}_{2} \text { uptake }=m\left[\mathrm{CO}_{2}\right]_{\text {post-carbonation }}-m\left[\mathrm{CO}_{2}\right]_{\text {prior to carbonation }}
$$

in which $m\left[\mathrm{CO}_{2}\right]$ is the mass loss percentage of samples from $530-900{ }^{\circ} \mathrm{C}$ in the TGDTG diagrams. The amount of $\mathrm{CO}_{2}$ uptake as the mass percentage of the samples as a function of carbonation time is plotted in Figure 11b. It can be seen that the $\mathrm{LC}^{3}$ pastes show considerably lower $\mathrm{CO}_{2}$ binding capacity than the OPC-counterpart, due to a comparatively low amount of calcium. Moreover, the incorporation of sulfate salts noticeably lowers the $\mathrm{CO}_{2}$ binding capacity of $\mathrm{LC}^{3}$ pastes, likely attributed to a lowered amount of hydration products due to a lower degree of hydration. This finding is in alignment with the previous observations that alkali cation shows a noticeable deleterious effect on slowing down the late hydration process. 

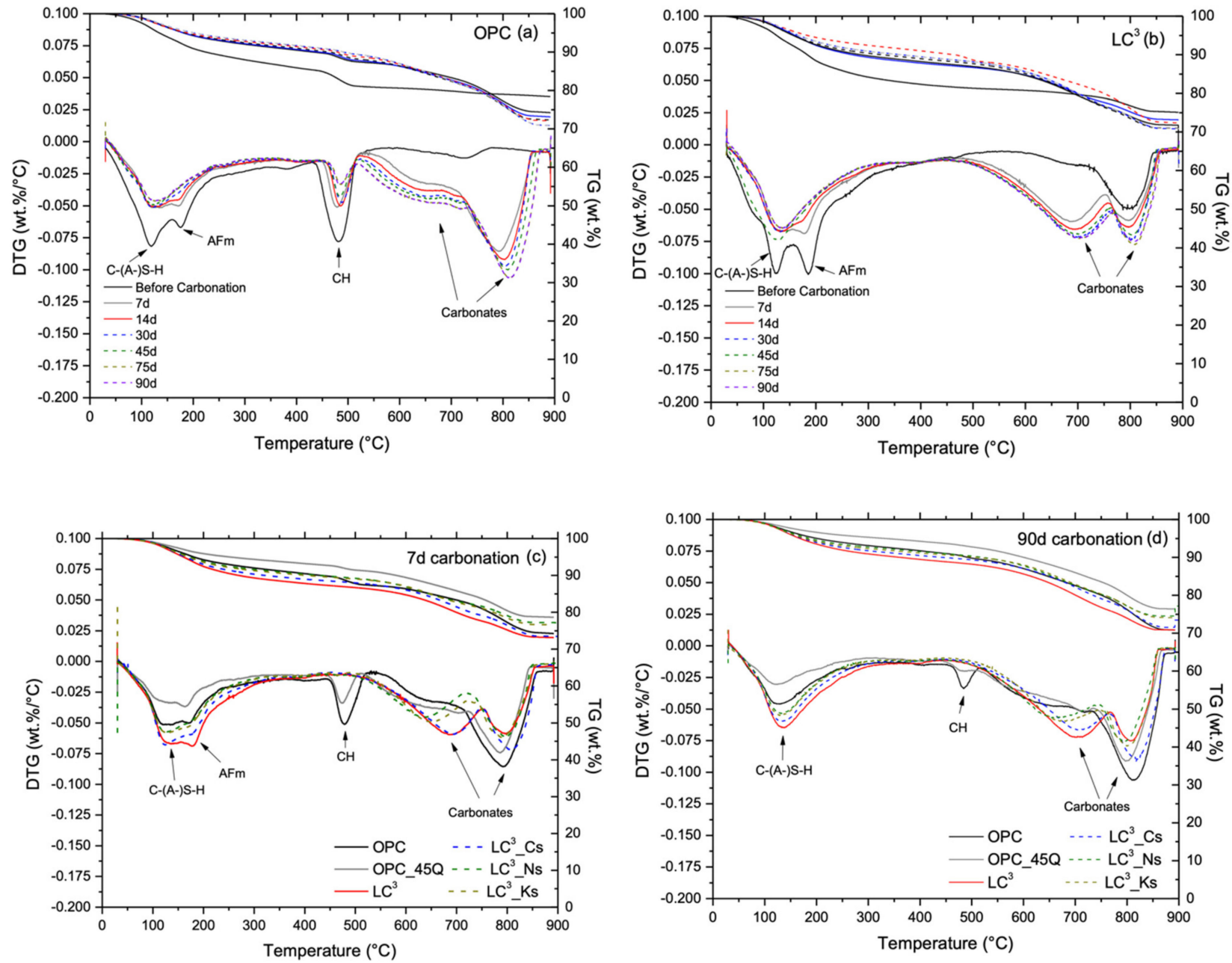

Figure 9. TG-DTG diagrams of reference OPC and $\mathrm{LC}^{3}$ pastes after carbonation. (a) OPC pastes at various carbonation period up to 90 days; (b) LC ${ }^{3}$ pastes at various carbonation period up to 90 days; (c) All mixtures after 7 days carbonation; (d) All mixtures after 90 days carbonation.

The FTIR spectra show a magnified increase of hump intensity related to C-O bonds, due to the intensive formation of carbonates in the carbonated pastes. Moreover, the hump assigned to the in-plane stretching vibration of the $\mathrm{Q}_{2}$ tetrahedra in C-A-S-H products in $\mathrm{LC}^{3}$ shifts from $970 \mathrm{~cm}^{-1}$ to $1000 \mathrm{~cm}^{-1}$ upon carbonation, in comparison to that of reference OPC paste. This shift in the wavenumber indicates an alteration of the molecular structure of C-A-S-H in $\mathrm{LC}^{3}$ pastes, due to carbonation-induced decalcification.

\subsection{Pore Structure Alterations}

The MIP pore size distributions of reference OPC and $\mathrm{LC}^{3}$ pastes without and with natural carbonation are compared in Figure 12. The comparison of pore structures of non-carbonated OPC and $\mathrm{LC}^{3}$ pastes with the same $\mathrm{w} / \mathrm{p}$ ratio has been reported in the literature, suggesting that $\mathrm{LC}^{3}$ generally has a refined pore structure than OPC-counterparts at late ages, owing to the physiochemical roles of MK $[3,45,46]$. In non-carbonated states, the incorporation of sulfate salts noticeably enlarges the porosity and coarsens the pore structure of $\mathrm{LC}^{3}$, particularly for the $\mathrm{Na}_{2} \mathrm{SO}_{4}$ and $\mathrm{K}_{2} \mathrm{SO}_{4}$ salts. This coarsening effect on pore structure is reflected well by the lowered compressive strengths at later ages of $\mathrm{LC}^{3}$ pastes containing $\mathrm{Na}_{2} \mathrm{SO}_{4}$ and $\mathrm{K}_{2} \mathrm{SO}_{4}$ salts. Moreover, the coarsened pore structure can further undermine the carbonation resistance of $\mathrm{LC}^{3}$ pastes containing $\mathrm{Na}_{2} \mathrm{SO}_{4}$ and $\mathrm{K}_{2} \mathrm{SO}_{4}$ salts by facilitating the transport of gaseous $\mathrm{CO}_{2}$ into the interiors of exposed specimens, thus leading to a deepened carbonation depth. 

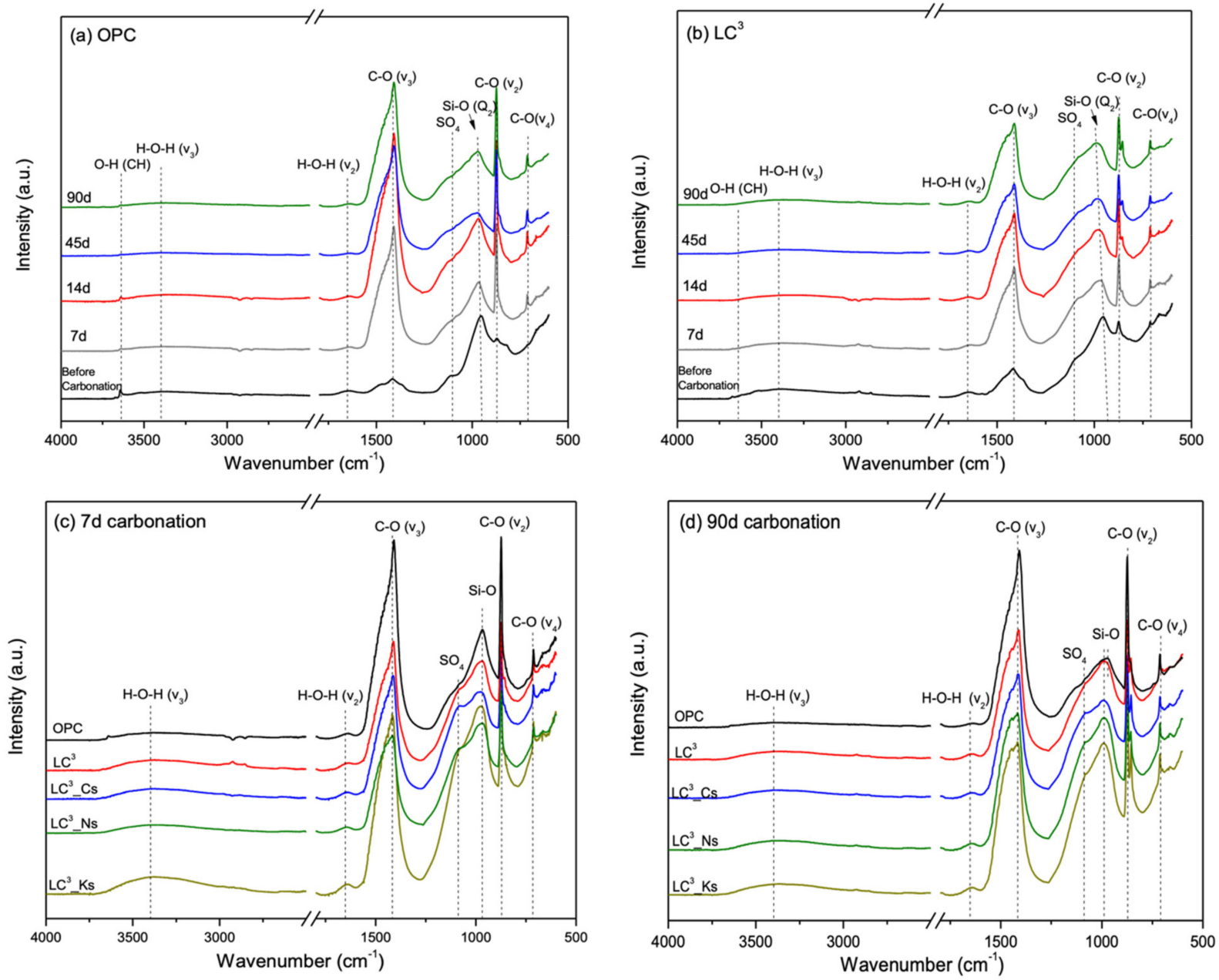

Figure 10. FTIR spectra of reference OPC and $\mathrm{LC}^{3}$ pastes after natural carbonation for (a) 7 days; (b) 90 days; (c) All mixtures after 7 days carbonation; (d) All mixtures after 90 days carbonation.
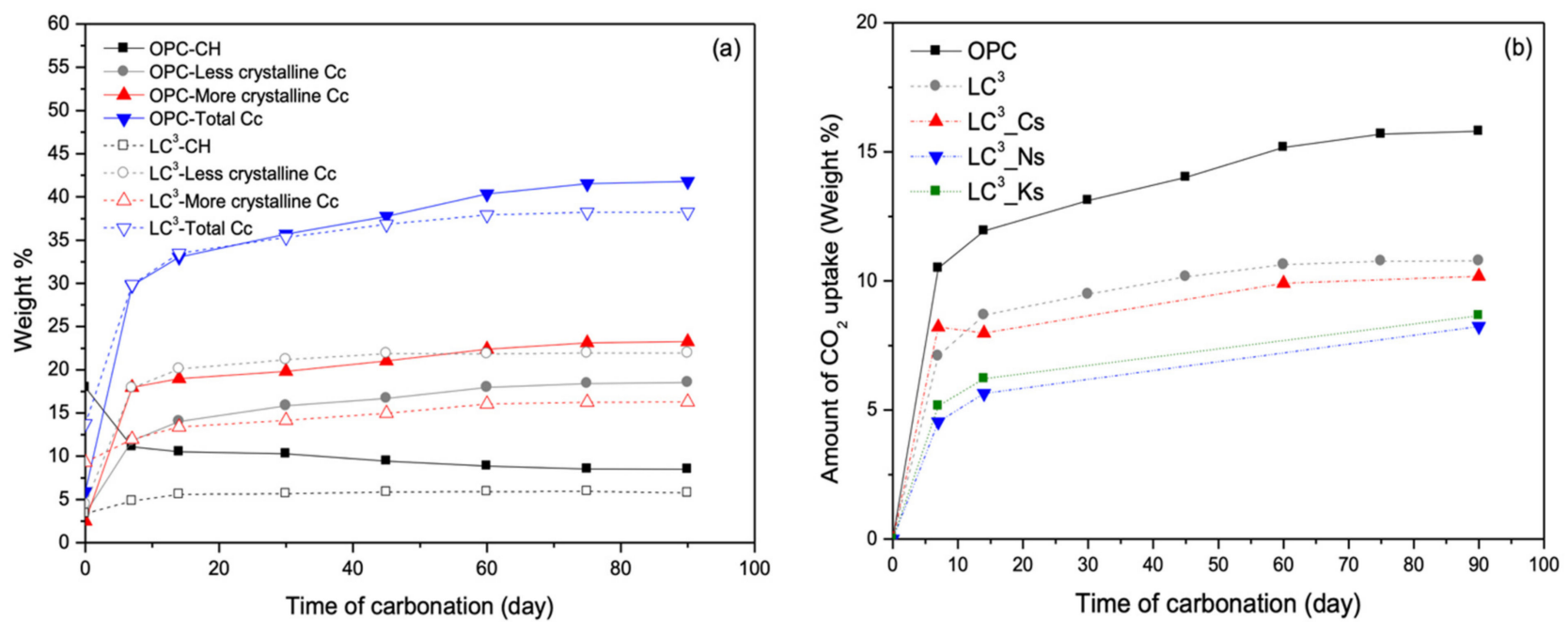

Figure 11. (a) The carbonation-induced evolution of mass percentages of $\mathrm{CH}$, less-crystalline $\mathrm{Cc}$, more-crystalline $\mathrm{Cc}$, and total Cc over time in reference OPC and $\mathrm{LC}^{3}$ pastes; (b) The amount of $\mathrm{CO}_{2}$ uptake in $\mathrm{LC}^{3}$ paste containing various alkalis salts as a function of carbonation time. 

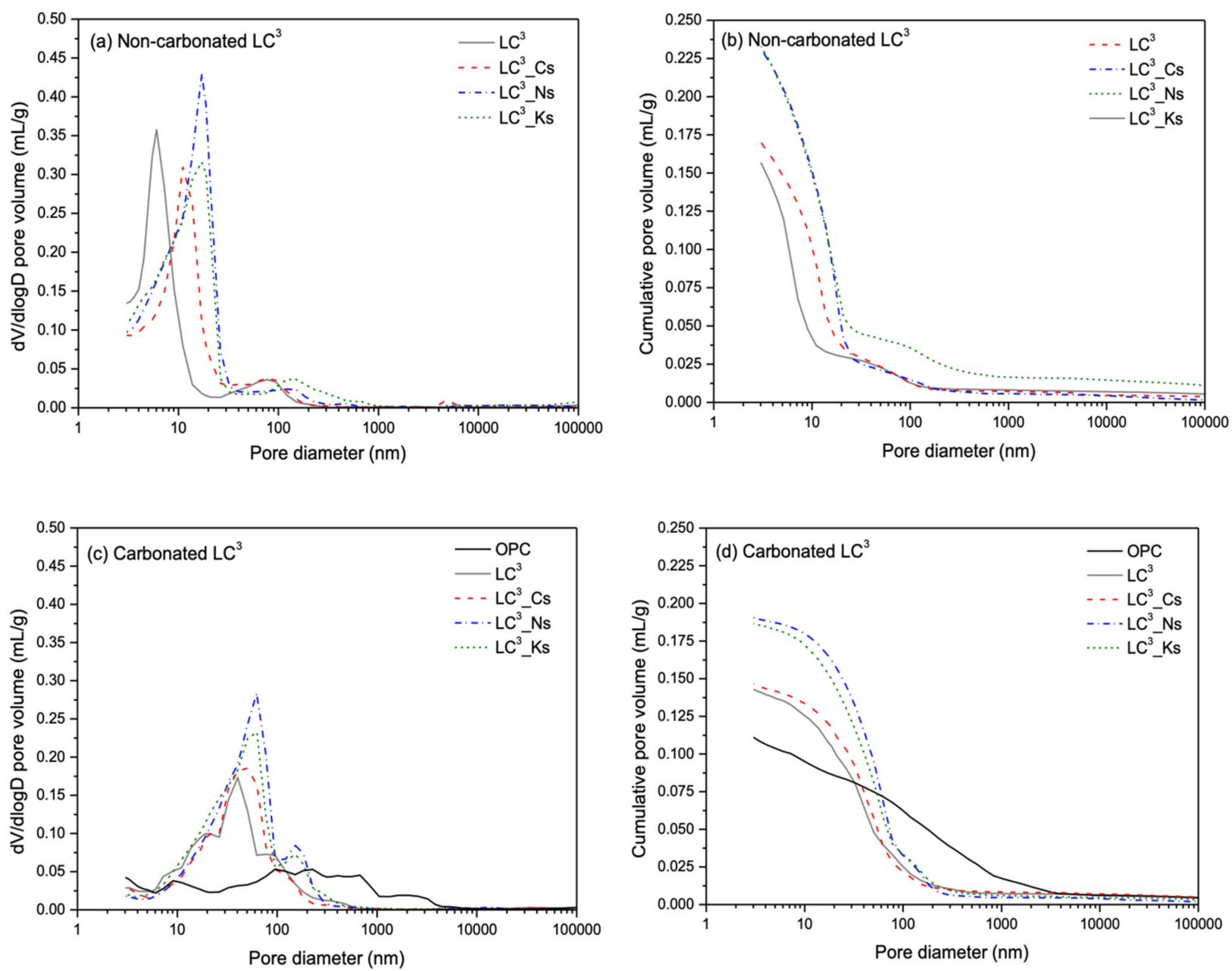

Figure 12. MIP pore size distributions of reference OPC and $L^{3}$ pastes $(\mathbf{a}, \mathbf{b})$ without carbonation $(27$ weeks of sealed curing); (c,d) reference OPC and LC ${ }^{3}$ pastes with natural carbonation (23 weeks of natural carbonation following 28 days of sealed curing).

Natural carbonation leads to a reduced MIP porosity and coarsened pore structure in $\mathrm{LC}^{3}$ pastes, similar to the findings for OPC pastes. The reduction in porosity may be attributed to the pore filling effects of $\mathrm{Cc}$ and/or alkali-doped Cc crystals; while the pore coarsening effects may be attributed to the decalcification-induced polymerization of C-S-H and C-A-S-H $[44,47,48]$.

\subsection{Microstructure Analyses at the Carbonation Skin}

Figure 13 shows the backscattered electron (BSE) images of reference OPC and LC 3 pastes after 23 weeks of natural carbonation. In the reference OPC paste, three distinctive zones with varying carbonation levels and morphologies can be identified. The outermost carbonation zone (zone I) is highly porous, due to the dissolution of $\mathrm{CH}$ and decalcification of C-S-H; the intermediate zone (zone II) is the densest due to precipitation of Cc filling the pores, while the innermost zone (zone III) is the most intact [43,49]. In the LC $^{3}$ paste, distinctive zones with a progressively increased level of carbonation inward can also be identified. However, the zone with densified microstructure (corresponding to zone II in OPC systems) is not unequivocally observed. This is probably due to the virtual absence of $\mathrm{CH}$ in the $\mathrm{LC}^{3}$ systems, and thus insufficient amount of formed $\mathrm{Cc}$ that could fully fill the pores in microstructure. It should be noted that the intact zone for $\mathrm{LC}^{3}$ is not shown in Figure 13 due to the deep carbonation depth. 

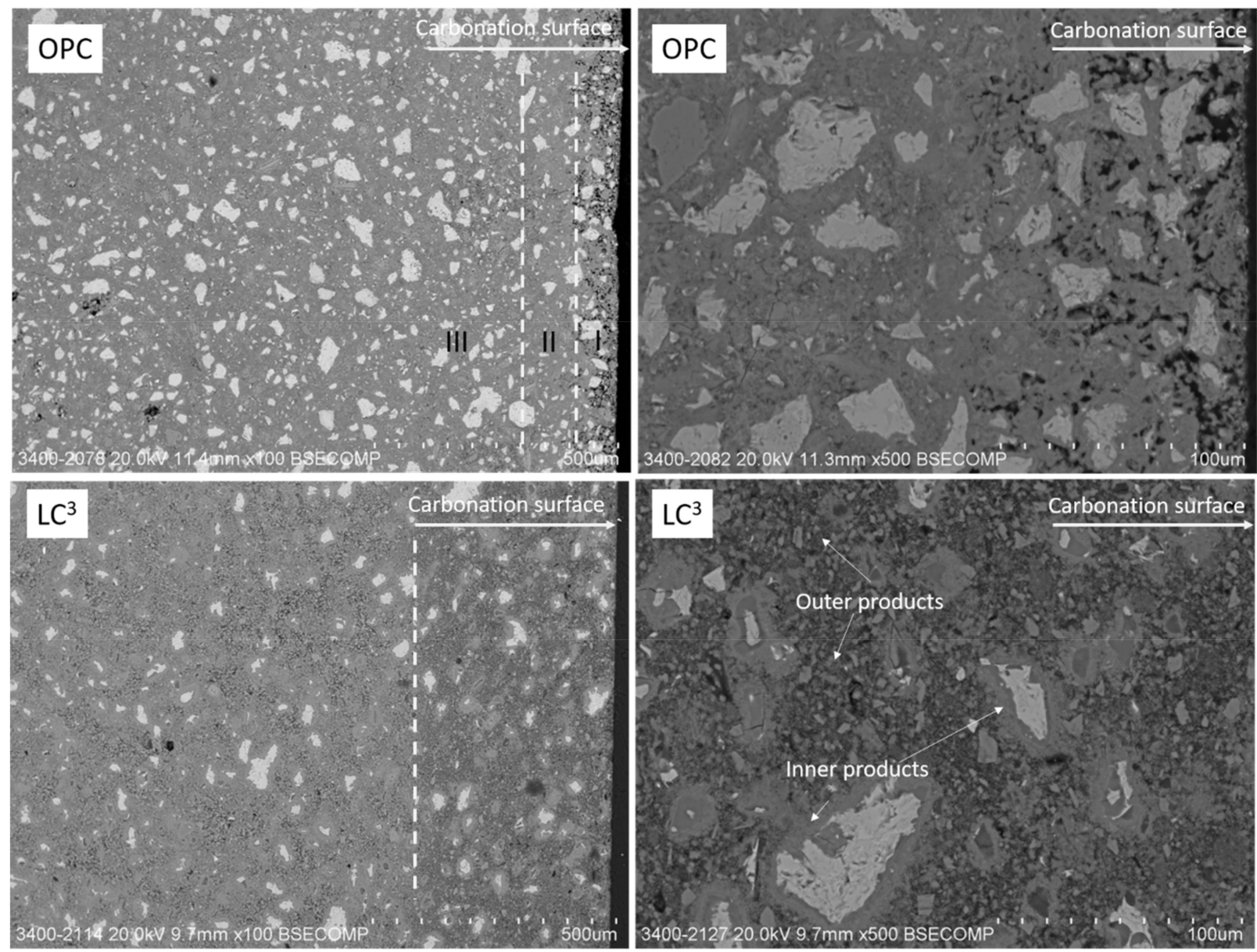

Figure 13. Backscattered electron images of reference OPC and $\mathrm{LC}^{3}$ pastes after 23 weeks of natural carbonation with a magnification of $\times 100$ and $\times 500$.

In the carbonated zone of $\mathrm{LC}^{3}$ pastes, a highly heterogeneous microstructure can be observed, in which the denser rims (inner products) surrounding the unreacted clinkers, while a porous region (outer products) with Cc precipitates manifested between cement particles. Figure 14 shows the SEM-EDS elemental mapping of carbonated LC ${ }^{3}$ pastes, in which the particles of unreacted OPC clinkers, MK, and LS can be identified. It can be seen that the inner product is mainly rich in calcium, silicon, and sulfate, while the outer product is more enriched in alumina. Such a difference in composition indicates that the hydrated phase distribution in the microstructure of $\mathrm{LC}^{3}$ pastes is highly heterogenous. This is reasonable considering the hydration mechanisms of the $\mathrm{LC}^{3}$ composite. More specifically, the hydration of OPC clinkers forms the inner products surrounding the hydrating grains, composed of mainly C-S-H, minor $\mathrm{CH}$, while the outer products are mainly composed of C-A-S-H, AFm phases (mainly $\mathrm{C}_{2} \mathrm{ASH}_{8}$ and $\mathrm{C}_{4} \mathrm{Ac}_{0.5} \mathrm{H}_{12}$ ) from the reaction of MK and LS, in an alkaline condition created by hydrating OPC. Due to the almost absence of $\mathrm{CH}$ and relatively lower calcium content, the outer products are carbonated much faster, rendering a more porous morphology. 

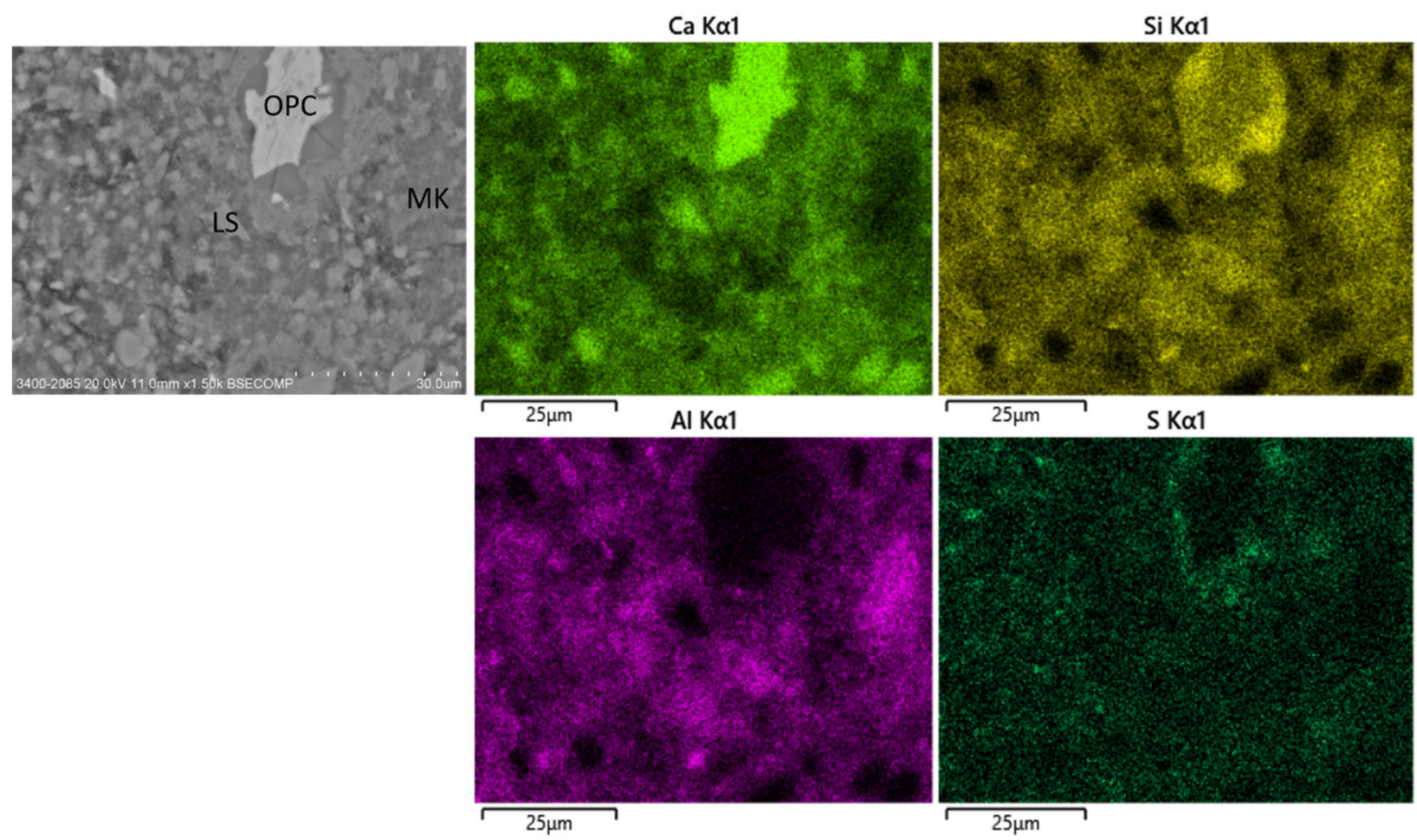

Figure 14. Backscattered electron image and elemental mapping of $\mathrm{LC}^{3}-\mathrm{Ns}$ pastes.

Figure 15 displays the $\mathrm{Si} / \mathrm{Ca}$ versus $\mathrm{Al} / \mathrm{Ca}$ plots of reacted products in the microstructure of non-carbonated and carbonated $\mathrm{LC}^{3}$ pastes. It should be noted that for noncarbonated $\mathrm{LC}^{3}$ specimens, no distinction is unequivocally made between the inner and outer products due to their similarity in grey levels in BSE images. A strong linear correlation between the $\mathrm{Si} / \mathrm{Ca}$ versus $\mathrm{Al} / \mathrm{Ca}$ is observed in the non-carbonated $\mathrm{LC}^{3}$ pastes, as well as in the outer products of carbonated pastes. The slope of the elemental plot indicating the overall $\mathrm{Al} / \mathrm{Si}$ molar ratio is $\sim 0.7$, which implies the intermixing of various phases including C-A-S-H, AFm phases, and potentially unreacted MK fine particles. Upon carbonation, the inner products are comprised of probably slightly decalcified C-S-H and $\mathrm{Cc}$ due to carbonation of $\mathrm{CH}$, while the outer product is carbonated into highly decalcified C-A-S-H and precipitates of Cc crystals. Moreover, the carbonation of outer product has little influence on the $\mathrm{Al} / \mathrm{Si}$ ratio of the carbonated phases. 

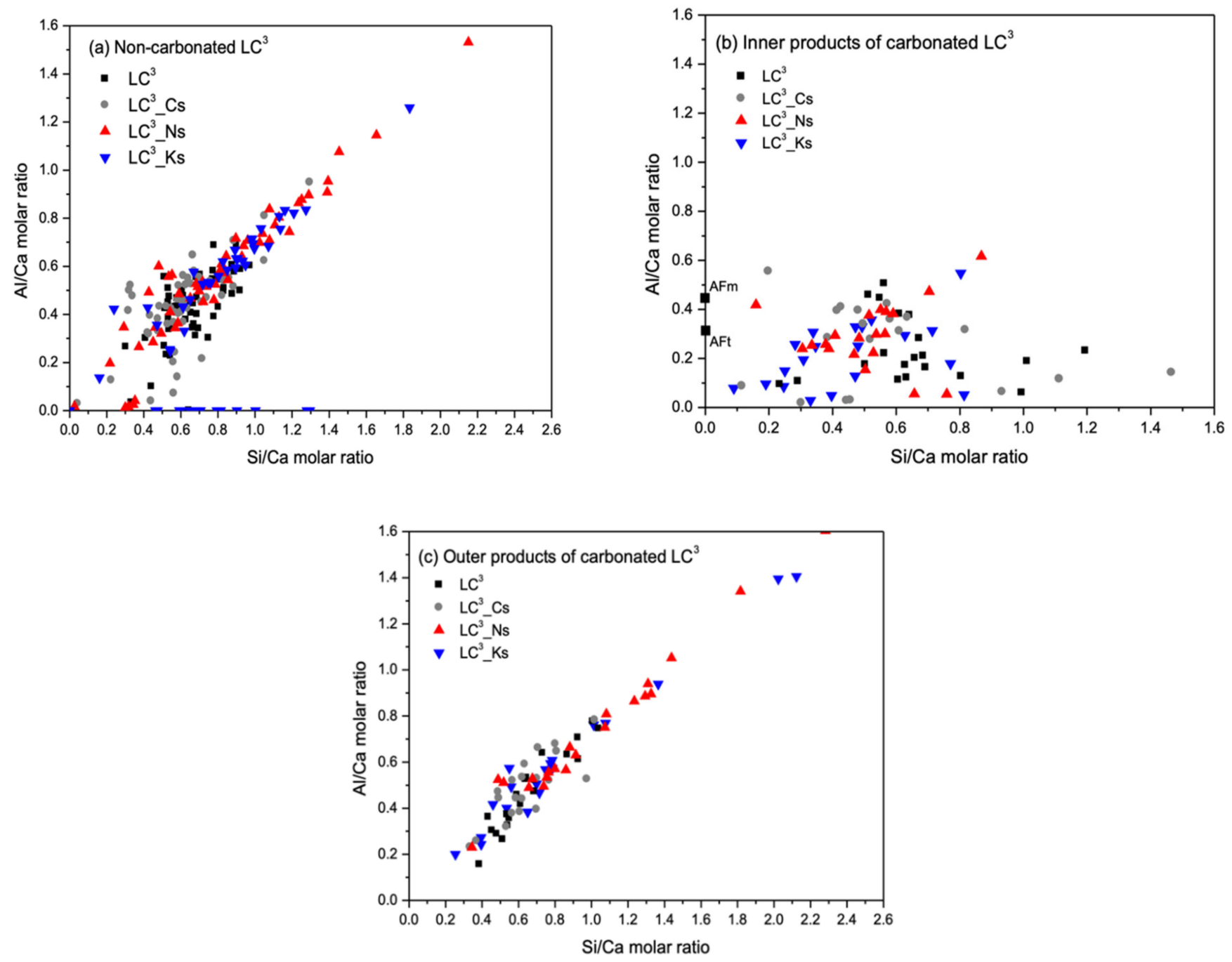

Figure 15. SEM-EDS Si/Ca versus $\mathrm{Al} / \mathrm{Ca}$ molar ratio plots of reacted products in the microstructure of $\mathrm{LC}^{3}$ pastes containing various sulfate salts. (a) Non-carbonated specimens at ages of 27 weeks; (b) Inner products of specimens after being carbonated for 23 weeks after 28 days of sealed curing; (c) Outer products of specimens after being carbonated for 23 weeks after 28 days of sealed curing.

\section{Conclusions}

In this work, the influence of three sulfate salts (i.e., $\mathrm{CaSO}_{4}, \mathrm{Na}_{2} \mathrm{SO}_{4}$, and $\mathrm{K}_{2} \mathrm{SO}_{4}$ ) on the natural carbonation behaviors of $\mathrm{LC}^{3}$ systems is studied. In addition, the natural carbonation process and mechanisms of $\mathrm{LC}^{3}$ systems containing sulfate salts are discussed. The following conclusions can be drawn based on this work.

(1) The incorporation of sulfate salts considerably accelerates setting and strength gain of $\mathrm{LC}^{3}$ systems, but undermines its later age strength. The early strength acceleration in $\mathrm{LC}^{3}$ by sulfate salts is likely due to enhanced ettringite formation with supplemented sulfate; however, the reduced later age strength is likely due to the deleterious effects of alkali ions (i.e., $\mathrm{Na}^{+}$and $\mathrm{K}^{+}$) on the diffusion-controlled OPC hydration process.

(2) The carbonation resistance of $\mathrm{LC}^{3}$ systems is noticeably compromised with the incorporation of sodium or potassium sulfate salts, mainly due to the pore structure coarsening effect and reduced $\mathrm{CO}_{2}$-binding capacity.

(3) In comparison to calcium sulfate, the negative effects of $\mathrm{Na}_{2} \mathrm{SO}_{4}$, and $\mathrm{K}_{2} \mathrm{SO}_{4}$ on carbonation resistance of $\mathrm{LC}^{3}$ are more significant. As such, limiting the alkali content in $\mathrm{LC}^{3}$ systems is recommended, concerning the durability requirement against carbonation-induced materials degradations. 
(4) Carbonation of OPC and $\mathrm{LC}^{3}$ pastes containing various alkalis leads to a considerable reduction of porosity and coarsening of pore structure, as revealed by MIP results.

(5) Reference OPC and $\mathrm{LC}^{3}$ pastes show different microstructure characteristics at carbonation layers. Distinctive carbonated products (inner and outer products) can be identified in the microstructure of $\mathrm{LC}^{3}$ pastes, implying a highly heterogeneous distribution of hydrates phases prior to carbonation. The inner product is mainly composed of C-S-H and $\mathrm{CH}$ from hydration of OPC clinkers, while the outer product is composed of C-A-S-H and AFm phases from LS and MK hydration in an alkaline condition created by hydrating OPC. The carbonation of outer product results in considerable decalcification via calcium carbonate formation, but has little influence on the $\mathrm{Al} / \mathrm{Si}$ ratio of the carbonated phases.

Author Contributions: R.L.: experimentation; investigation; formal analysis; visualization; writingoriginal draft preparation. H.Y.: supervision; supervision; writing-review and editing. All authors have read and agreed to the published version of the manuscript.

Funding: This work was supported by The University of Hong Kong through Undergraduate Research Fellowship Programme (URFP) (Fellowship Awardee: R.L.). Any opinions, findings and conclusions or recommendations expressed in this material are those of the authors and do not necessarily reflect the views of the sponsors.

Institutional Review Board Statement: Not applicable.

Informed Consent Statement: Not applicable.

Data Availability Statement: All data, models, and code generated or used during the study appear in the submitted article.

Acknowledgments: R.L. would like to thank the supports from Undergraduate Research Fellowship Programme (URFP), The University of Hong Kong.

Conflicts of Interest: The authors declare no conflict of interest.

\section{References}

1. Cancio Díaz, Y.; Sánchez Berriel, S.; Heierli, U.; Favier, A.R.; Sánchez Machado, I.R.; Scrivener, K.L.; Martirena Hernández, J.F.; Habert, G. Limestone calcined clay cement as a low-carbon solution to meet expanding cement demand in emerging economies. Dev. Eng. 2017, 2, 82-91. [CrossRef]

2. Sharma, M.; Bishnoi, S.; Martirena, F.; Scrivener, K. Limestone calcined clay cement and concrete: A state-of-the-art review. Cem. Concr. Res. 2021, 149, 106564. [CrossRef]

3. Antoni, M.; Rossen, J.; Martirena, F.; Scrivener, K. Cement substitution by a combination of metakaolin and limestone. Cem. Concr. Res. 2012, 42, 1579-1589. [CrossRef]

4. Scrivener, K.; Martirena, F.; Bishnoi, S.; Maity, S. Calcined clay limestone cements (LC3). Cem. Concr. Res. 2018, 114, 49-56. [CrossRef]

5. Nguyen, Q.D.; Khan, M.S.H.; Castel, A. Chloride Diffusion in Limestone Flash Calcined Clay Cement Concrete. ACI Mater. J. 2020, 117, 165-175. [CrossRef]

6. Shi, Z.; Geiker, M.R.; De Weerdt, K.; Lothenbach, B.; Kaufmann, J.; Kunther, W.; Ferreiro, S.; Herfort, D.; Skibsted, J. Durability of Portland Cement Blends Including Calcined Clay and Limestone: Interactions with Sulfate, Chloride and Carbonate Ions. In Calcined Clays for Sustainable Concrete; Scrivener, K., Favier, A., Eds.; Springer: Singapore, 2015; pp. $133-141$.

7. Díaz, E.; González, R.; Rocha, D.; Alujas, A.; Martirena, F. Carbonation of concrete with low carbon cement LC3 exposed to dif-ferent environmental conditions. In Calcined Clays for Sustainable Concrete; Springer: Dordrecht, The Netherlands, 2018; pp. 141-146.

8. Shi, Z.; Lothenbach, B.; Geiker, M.R.; Kaufmann, J.; Leemann, A.; Ferreiro, S.; Skibsted, J. Experimental studies and thermodynamic modeling of the carbonation of Portland cement, metakaolin and limestone mortars. Cem. Concr. Res. 2016, 88, 60-72. [CrossRef]

9. Fu, C.; Fang, D.; Ye, H.; Huang, L.; Wang, J. Bond degradation of non-uniformly corroded steel rebars in concrete. Eng. Struct. 2021, 226, 111392. [CrossRef]

10. Nguyen, Q.D.; Castel, A. Reinforcement corrosion in limestone flash calcined clay cement-based concrete. Cem. Concr. Res. 2020, 132, 106051. [CrossRef]

11. Ye, H.; Jin, X.; Fu, C.; Jin, N.; Xu, Y.; Huang, T. Chloride penetration in concrete exposed to cyclic drying-wetting and carbonation. Constr. Build. Mater. 2016, 112, 457-463. [CrossRef] 
12. Ye, H.; Radlińska, A. Effect of Alkalis on Cementitious Materials:Understanding the Relationship between Composition, Structure, and Volume Change Mechanism. J. Adv. Concr. Technol. 2017, 15, 165-177. [CrossRef]

13. Jawed, I.; Skalny, J. Alkalies in cement: A review: II. Effects of alkalies on hydration and performance of Portland cement. Cem. Concr. Res. 1978, 8, 37-51. [CrossRef]

14. Maslehuddin, M.; Page, C.L. Rasheeduzzafar Effect of Temperature and Salt Contamination on Carbonation of Cements. J. Mater. Civ. Eng. 1996, 8, 63-69. [CrossRef]

15. Dow, C.; Glasser, F. Calcium carbonate efflorescence on Portland cement and building materials. Cem. Concr. Res. 2003, 33, 147-154. [CrossRef]

16. Krishnan, S.; Singh, A.; Bishnoi, S. Impact of Alkali Salts on the Hydration of Ordinary Portland Cement and Limestone-Calcined Clay Cement. J. Mater. Civ. Eng. 2021, 33, 04021223. [CrossRef]

17. Schulze, S.E.; Rickert, J. Suitability of natural calcined clays as supplementary cementitious material. Cem. Concr. Compos. 2019, 95, 92-97. [CrossRef]

18. Rajabipour, F.; Giannini, E.; Dunant, C.; Ideker, J.; Thomas, M.D. Alkali-silica reaction: Current understanding of the reaction mechanisms and the knowledge gaps. Cem. Concr. Res. 2015, 76, 130-146. [CrossRef]

19. Zunino, F.; Scrivener, K. Factors influencing the sulfate balance in pure phase C3S/C3A systems. Cem. Concr. Res. 2020, 133, 106085. [CrossRef]

20. ASTM Standard C191. Standard Test Method for Time of Setting of Hydraulic Cement by Vicat Needle; ASTM International: West Conshohocken, PA, USA, 2019.

21. Hidalgo, A.; Domingo, C.; García-González, C.A.; Petit, S.; Andrade, C.; Alonso, C. Microstructural changes induced in Portland cement-based materials due to natural and supercritical carbonation. J. Mater. Sci. 2008, 43, 3101-3111. [CrossRef]

22. Ye, H.; Cai, R.; Tian, Z. Natural carbonation-induced phase and molecular evolution of alkali-activated slag: Effect of activator composition and curing temperature. Constr. Build. Mater. 2020, 248, 118726. [CrossRef]

23. Choi, J.-I.; Lee, Y.; Kim, Y.Y.; Lee, B.Y. Image-processing technique to detect carbonation regions of concrete sprayed with a phenolphthalein solution. Constr. Build. Mater. 2017, 154, 451-461. [CrossRef]

24. Scrivener, K.; Snellings, R.; Lothenbach, B. A Practical Guide to Microstructural Analysis of Cementitious Materials; CRC Press: Boca Raton, FL, USA, 2018.

25. Aligizaki, K.K. Pore Structure of Cement-Based Materials: Testing, Interpretation and Requirements; CRC Press: Boca Raton, FL, USA, 2014.

26. Gallé, C. Effect of drying on cement-based materials pore structure as identified by mercury intrusion porosimetry: A comparative study between oven-, vacuum-, and freeze-drying. Cem. Concr. Res. 2001, 31, 1467-1477. [CrossRef]

27. Dhandapani, Y.; Sakthivel, T.; Santhanam, M.; Gettu, R.; Pillai, R.G. Mechanical properties and durability performance of con-cretes with Limestone Calcined Clay Cement (LC3). Cem. Concr. Res. 2018, 107, 136-151. [CrossRef]

28. Wang, L.; Rehman, N.U.; Curosu, I.; Zhu, Z.; Beigh, M.A.B.; Liebscher, M.; Chen, L.; Tsang, D.C.; Hempel, S.; Mechtcherine, V. On the use of limestone calcined clay cement (LC3) in high-strength strain-hardening cement-based composites (HS-SHCC). Cem. Concr. Res. 2021, 144, 106421. [CrossRef]

29. Emmanuel, A.C.; Haldar, P.; Maity, S.; Bishnoi, S. Second pilot production of limestone calcined clay cement in India: The expe-rience. Indian Concr. J 2016, 90, 57-64.

30. Ye, H. Autogenous formation and smart behaviors of nitrite- and nitrate-intercalated layered double hydroxides (LDHs) in Port-land cement-metakaolin-dolomite blends. Cem. Concr. Res. 2021, 139, 106267. [CrossRef]

31. Mota, B.; Matschei, T.; Scrivener, K. Impact of $\mathrm{NaOH}$ and $\mathrm{Na} 2 \mathrm{SO} 4$ on the kinetics and microstructural development of white cement hydration. Cem. Concr. Res. 2018, 108, 172-185. [CrossRef]

32. Ye, H.; Radlińska, A.; Neves, J. Drying and carbonation shrinkage of cement paste containing alkalis. Mater. Struct. 2017, 50, 50. [CrossRef]

33. Tironi, A.; Scian, A.N.; Irassar, E.F. Blended Cements with Limestone Filler and Kaolinitic Calcined Clay: Filler and Pozzolanic Effects. J. Mater. Civ. Eng. 2017, 29, 04017116. [CrossRef]

34. Huang, L.; Yan, P. Effect of alkali content in cement on its hydration kinetics and mechanical properties. Constr. Build. Mater. 2019, 228, 116833. [CrossRef]

35. Zajac, M.; Skocek, J.; Lothenbach, B.; Mohsen, B.H. Late hydration kinetics: Indications from thermodynamic analysis of pore solution data. Cem. Concr. Res. 2020, 129, 105975. [CrossRef]

36. Zunino, F.; Scrivener, K. The reaction between metakaolin and limestone and its effect in porosity refinement and mechanical properties. Cem. Concr. Res. 2021, 140, 106307. [CrossRef]

37. Matschei, T.; Lothenbach, B.; Glasser, F. The AFm phase in Portland cement. Cem. Concr. Res. 2007, 37, 118-130. [CrossRef]

38. Lodeiro, I.G.; Macphee, D.E.; Palomo, A.; Fernández-Jiménez, A. Effect of alkalis on fresh C-S-H gels. FTIR analysis. Cem. Concr. Res. 2009, 39, 147-153. [CrossRef]

39. Yu, P.; Kirkpatrick, R.J.; Poe, B.; McMillan, P.F.; Cong, X. Structure of calcium silicate hydrate (C-S-H): Near-, Mid-, and Far-infrared spectroscopy. J. Am. Ceram. Soc. 1999, 82, 742-748. [CrossRef]

40. Ghosh, S.N.; Handoo, S.K. Infrared and Raman spectral studies in cement and concrete (review). Cem. Concr. Res. 1980, 10, 771-782. [CrossRef] 
41. Hughes, T.L.; Methven, C.M.; Jones, T.G.; Pelham, S.E.; Fletcher, P.; Hall, C. Determining cement composition by Fourier transform infrared spectroscopy. Adv. Cem. Based Mater. 1995, 2, 91-104. [CrossRef]

42. Villain, G.; Thiery, M.; Platret, G. Measurement methods of carbonation profiles in concrete: Thermogravimetry, chemical analysis and gammadensimetry. Cem. Concr. Res. 2007, 37, 1182-1192. [CrossRef]

43. Chang, C.-F.; Chen, J.-W. The experimental investigation of concrete carbonation depth. Cem. Concr. Res. 2006, 36, $1760-1767$. [CrossRef]

44. Shah, V.; Scrivener, K.; Bhattacharjee, B.; Bishnoi, S. Changes in microstructure characteristics of cement paste on carbonation. Cem. Concr. Res. 2018, 109, 184-197. [CrossRef]

45. Dhandapani, Y.; Santhanam, M. Assessment of pore structure evolution in the limestone calcined clay cementitious system and its implications for performance. Cem. Concr. Compos. 2017, 84, 36-47. [CrossRef]

46. Cai, R.; Tian, Z.; Ye, H.; He, Z.; Tang, S. The role of metakaolin in pore structure evolution of Portland cement pastes revealed by an impedance approach. Cem. Concr. Compos. 2021, 119, 103999. [CrossRef]

47. Ngala, V.; Page, C. Effects of carbonation on pore structure and diffusional properties of hydrated cement pastes. Cem. Concr. Res. 1997, 27, 995-1007. [CrossRef]

48. Chindaprasirt, P.; Rukzon, S. Pore Structure Changes of Blended Cement Pastes Containing Fly Ash, Rice Husk Ash, and Palm Oil Fuel Ash Caused by Carbonation. J. Mater. Civ. Eng. 2009, 21, 666-671. [CrossRef]

49. Kutchko, B.G.; Strazisar, B.R.; Dzombak, D.A.; Lowry, G.V.; Thaulow, N. Degradation of Well Cement by CO2 under Geologic Sequestration Conditions. Environ. Sci. Technol. 2007, 41, 4787-4792. [CrossRef] 